\title{
Becoming Parents in NICU During the COVID-19 Pandemic: Challenges and Opportunities
}

\author{
Ancora G, Simeone N.
}

Neonatal Intensive Care Unit, AUSL Romagna, Infermi Hospital,Rimini, Italy

\section{Background}

During the COVID-19 pandemic many hospitals in Italy restricted parental access to Newborn Intensive Care Units (NICU). In the best of cases parents have been allowed to stay with their babies only one parent at a time, wearing face masks. Fathers were mostly hampered by the restrictive visiting polices, although their role in providing emotional support to mothers is well recognized. In addition, a good relationship between fathers and newborns will improve children's ability to regulate their emotions and impulses.

\section{Aims/Purpose}

To report challenges and opportunities in performing Family Centered Care in a level III Italian NICU during the COVID-19 pandemic outbreak.

\section{Methods}

During the lockdown period the level III NICU in Rimini remained open for parents 24 hours a day. As opposed to the pre-COVID-19 period, only one parent could take care of their baby at a time and were asked to wear a face mask. This new policy became necessary because of legislative and logistic reasons (eg., very small spaces in the Unit). To cope with the new situation we put in place several strategies: empowering parents; regular multidisciplinary meetings with both parents; staff support by means of weekly staff briefings and the administration of a symptom checklist to the healthcare team before and after a mindfulness intervention performed prior to the COVID-19 pandemic, and re-administered during the pandemic outbreak; early hospital discharge including home visits. Non-structured interviews of fathers were also performed by a NIDCAP professional to explore father's feelings.

\section{Results}

During a two-months period (March-April 2020) eight VLBW infants (Birthweight 943 \pm 341 grams, Gestational Age $26 \pm 2$ weeks) were admitted to the NICU. Parents origin was heterogeneous: two from Italy, one from Albania, one from France, one from Senegal, one from China, and two from Brazil. All mothers practiced skin-to-skin contact (SSC) with their babies, initiated at $9 \pm 6$ days; $6 / 8$ fathers initiated the SSC at $13 \pm 6$ days. Moreover, all fathers and mothers performed daily care for their babies (eg., tube feeding, nappy change). Fathers' interviews unveiled a loving engagement with their babies ("At the beginning I was loath to touch my baby, but now I enjoy physical contact with him. I am also able to manage the nasal prongs. Now, I'd like to stay always in SSC, because it gives me a sense of safety and helps me to prepare to go home with him"; "Taking care of him helps me to be in tune with nurses"; "I'm happy to stay in SSC with my daughter, if I could I'll do it continuously. I love to give her a delicate massage behind the ear"). The symptom checklist administered to the healthcare team showed that the interventions was efficacious in reducing the anxiety score which remained stable during the COVID-19 period.

\section{Conclusion}

During the COVID-19 pandemic, missing facial expressions because of facial masks, made it difficult to modulate verbal communication with parents and to interpret parents' reaction to communication; moreover, at the bedside, parents were alone in communicating with the staff, without the support of their partner, feeling the emotional burden of reporting updates about the baby to the whole family. This led to a higher degree of uncertainty, fragility, and lack of confidence among parents. Despite this, both parents became involved in their baby's care and staff did not show increased levels of stress during this period. Coping strategies implemented in the Unit could have contributed to these results. Moreover, during the COVID-19 period, fathers, without the mother's presence, took up the challenge of taking care of their babies as primary caregivers. In conclusion, staff/parent partnerships, in challenging situations, can produce surprising opportunities for families.

\footnotetext{
References:

1. Lavizzari A, Klingenberg C, Profit J, Zupancic JAF, Davis AS, Mosca F, Molloy EJ, Roehr CC, and The International Neonatal COVID-19 Consortium. International comparison of guidelines for managing neonates at the early phase of the SARS-CoV-2 pandemic. Pediatric Research, Published: 15 June 2020. DOI: 10.1038/s41390-020-0976-5

2. O'Brien K, Robson K, Bracht M, Cruz M, Lui K, Alvaro R, Da Silva O, Monterrosa L, Narvey M, Ng E, Soraisham A, Ye X Y, Mirea L, Tarnow-Mordi W, Lee S, and the FICare Study Group and FICare Parent Advisory Board. Effectiveness of Family Integrated Care in neonatal intensive care units on infant and parent outcomes: a multicentre, multinational, cluster-randomised controlled trial. Lancet Child Adolescent Health. 2018 Apr;2(4):245-254 DOI: $10.1016 / S 2352-4642(18) 30039-7$.

3. Fishera D, Khashue,f M, , Adamab EA, Feeleyc N , Garfieldd CF , Irelande JF, Kolioulig F, Lindbergh B, Nørgaardi B, Provenzi L, Thomson-Salok F, van Teijlingen E. Fathers in neonatal units: Improving infant health by supporting the babyfather bond and mother-father coparenting. Journal of Neonatal Nursing, 24 (6), 306-312. DOI: 10.1016/j.jnn.2018.08.007
}

SAVE THE DATES

The 32nd Annual NIDCAP Trainers Meeting Virtual Meeting

October 20-22, 2021

Check the NFI website for further details. www. nidcap.org

8 $2021 \cdot$ Developmental Observer 